\title{
Método multicritério de tomada de decisão: aplicação ao caso da localização espacial de uma Unidade de Pronto Atendimento - UPA $24 \mathrm{~h}$
}

\section{Multicriteria decision-making method: Application to the case of the spatial location of an Emergency Unit (UPA 24h)}

\author{
Rodrigo Amancio Briozo \\ Marcel Andreotti Musetti ${ }^{1}$
}

\begin{abstract}
Resumo: Este trabalho apresenta os resultados da aplicação de um método multicritério de tomada de decisão - Analytic Hierarchy Process- AHP, visando identificar o melhor local de instalação de uma Unidade de Pronto Atendimento - UPA $24 \mathrm{~h}$, com a participação de profissionais ligados à gestão pública de um município do interior do Estado de São Paulo. Para a consecução da pesquisa, houve a condução de reuniões junto aos participantes no intuito de 1) apresentar o método $A H P ; 2$ ) construir conjuntamente com os membros do grupo os critérios, subcritérios e identificar as alternativas de localização; 3) validar o modelo gerado; e 4) aplicar os questionários para obtenção do ranqueamento das alternativas de localização. A aplicação do método $A H P$ permitiu hierarquizar os locais candidatos, apresentando o "Local 1" como o mais bem ranqueado, servindo de subsídio para o gestor municipal tomar a decisão para a instalação da UPA 24 h.
\end{abstract}

Palavras-chave: Localização de instalações; Métodos multicritério para tomada de decisão; Método AHP; Unidade de Pronto Atendimento.

\begin{abstract}
This paper presents the results of applying a multicriteria decision-making method - Analytic Hierarchy Process (AHP) to identify the best location to install an Emergency Unit (UPA 24h), with the participation of professionals involved in the public management of a municipality in the state of Sao Paulo. To this end, workshops with participants were conducted in order to 1) present the AHP; 2) construct, together with the members of the group, the criteria and sub-criteria, and identify alternative locations; 3) validate the model generated; and 4) apply questionnaires to obtain the ranking of alternative locations. The application of AHP to the prioritization of candidate sites, presenting "Site 1" as the best ranked location, served as a subsidy for the municipal manager to make the decision for the installation of the Emergency Unit (UPA 24h).
\end{abstract}

Keywords: Location of facilities; Multicriteria decision-making methods - AHP; Emergency unit.

\section{Introdução}

A tomada de decisão sobre a localização de instalações, sejam elas públicas ou privadas, requer dos atores do processo o máximo de assertividade, dado o impacto que tal ação pode acarretar no médio e longo prazos, visto que a construção de um armazém, um prédio industrial, uma escola ou mesmo um hospital, impactam positiva ou negativamente por décadas após sua execução (Romero, 2006). Desta forma, a decisão de localização se realizada de forma subótima pode acarretar prejuízos e problemas graves, tanto para o tomador de decisão quanto para seus possíveis usuários.
O número de variáveis e critérios que são considerados no processo decisório para a localização tem aumentado nas últimas décadas, como regulamentação governamental, transporte, custos de mão de obra (Yang \& Lee, 1997), proximidade com varejistas, fatores ambientais, qualidade de vida (Chuang, 2001), critérios econômicos como proximidade a rede de telecomunicações, proximidade com fornecimento de energia elétrica (Covas et al., 2013).

As políticas públicas direcionadas para a construção de instalações públicas tais como escolas, corpo de bombeiros, correios, parques, praças, museus e, neste estudo, Unidades de Pronto Atendimento - UPA 24 h,

\footnotetext{
${ }^{1}$ Programa de Pós-Graduação em Engenharia de Produção - PPGEG, Escola de Engenharia de São Carlos - EESC, Universidade de São Paulo -USP, Av. Trabalhador são-carlense, 400, CEP 13566-590, São Carlos, SP, Brasil, e-mail: rodrigo.briozo@usp.br; musetti@sc.usp.br
}

Recebido em Set. 11, 2013 - Aceito em Maio 8, 2015

Suporte financeiro: $\mathrm{O}$ artigo foi desenvolvido com o apoio da CAPES, por meio de bolsa acadêmica. 
têm sido definidas ao longo da história do Brasil por critérios muito mais políticos do que técnicos (Fernandes, 2007).

Nesta ótica, a utilização de métodos multicritérios para tomada de decisão surgem como uma importante ferramenta para os gestores, minimizando os custos sociais no caso de órgãos públicos, ou maximizando o lucro, para o setor privado, diminuindo os riscos decorrentes de uma escolha errada na definição de localização.

A seguir, apresenta-se uma revisão bibliográfica sobre localização de instalações, métodos multicritérios para tomada de decisão, método Analytic Hierarchy Process - AHP, a aplicação do método $A H P$ para localização de instalações e, por fim, sobre as Unidades de Pronto Atendimento - UPA 24 h.

\section{Revisão bibliográfica}

\subsection{Localização de instalações}

A análise espacial de localização de instalações é crucial para a realização de uma boa gestão, seja para o setor privado ou público, sendo a localização ótima aquela que traz o maior benefício social, maximizando o nível de serviço prestado (Daskin, 1995).

Caso a localização de instalações ocorra de forma ineficaz, pode-se criar problemas de produtividade ou da prestação de serviços (Randhawa \& West, 1995). A análise estratégica dos locais candidatos a receber uma unidade produtiva ou de serviço é crucial para sua sobrevivência, pois a habilidade de muitas empresas em produzir e vender depende de sua localização (Klose \& Drexl, 2005), sendo fundamental a análise dinâmica da localização de instalações, prevenindo-se de possíveis transformações (Randhawa \& West, 1995).

As primeiras teorias relacionadas à localização de instalações, segundo Ballou (2001), começaram com economistas e geógrafos. Ainda segundo o autor, os primeiros pesquisadores que desenvolveram teorias que trabalhavam a localização espacial de instalações foram Johann von Thünen, Alfred Weber, Tord Folkeson Palander, August Losch, Edgar Hoover, Melvin Greenhut e Walter Isard. Estes pesquisadores davam enfoque aos custos de transportes na localização ideal para as instalações.

A localização de instalações se enquadra dentro do conceito de integração logística (Ballou, 2006). O número de instalações, sua localização e atribuição de produtos para cada unidade faz parte do design do sistema logístico (Closs \& Thompson, 1992).

No que tange às esferas públicas e privadas, existe uma diferenciação de foco para a localização de instalações. No setor público, o foco está nos custos não monetários e na demanda total atendida diferentemente do setor privado, no qual os custos de investimento e benefícios são medidos monetariamente (Daskin, 1995; Ross \& Soland, 1980). Rocha (2008) e Lorena et al. (2001) reforçam a diferença entre tais esferas, no que diz respeito à função objetivo, na modelagem matemática, na qual, para o setor privado, a função objetivo é a maximização da receita em detrimento da maximização da satisfação dos clientes que ocorre no setor público.

Segundo Ribeiro \& Antunes (2002), esforços para a localização de instalações públicas têm sido tomados com maior intensidade a partir de 1960, por diferentes áreas do conhecimento, como a pesquisa operacional, a gestão da ciência, a engenharia civil, a geografia econômica, o ordenamento do território, porém os gestores públicos ainda não tiram total proveito destes estudos.

Em relação à localização de unidades de saúde, a distância, para seus usuários, deve ser levada em consideração, pois é um dos fatores de maior importância, principalmente em países pobres e regiões carentes (Stock, 1983).

\subsection{Critérios, métodos e modelos para a localização de instalações}

Para a localização de instalações, existem critérios, métodos e modelos utilizados que auxiliam o tomador de decisão na execução de suas atividades. Segundo Yang \& Lee (1997), critérios como mercado, transporte, mão de obra, matéria-prima e regulamentação governamental devem ser levados em consideração na hora de decidir onde localizar uma instalação.

Randhawa \& West (1995) aponta critérios como minimização de custos, minimização de distâncias, impostos locais, exigências legais, atitudes da comunidade e condições de vida como importantes para localização de instalações. Chuang (2001) identifica como critérios quantitativos importantes para a localização de instalações os custos do terreno e imóveis, custos de transporte de entrada e saída, quantidade de abastecimento de suprimentos, proximidade com consumidores e varejistas, disponibilidade de mão de obra técnica necessária e, como critérios qualitativos, os fatores ambientais, a qualidade de vida e as políticas do governo.

Moreira (1996) aponta uma diferenciação nos critérios para localização de instalações industriais e unidades de prestação de serviço, sendo matéria-prima, água, energia e mão de obra critérios para o primeiro caso e proximidade com mercado consumidor, tráfego, e localização dos concorrentes para o segundo caso.

Para Ballou (2001), no caso de localização de unidades prestadoras de serviço, critérios como acessibilidade, disponibilidade de estacionamento, atitudes da comunidade, devem ser levados em consideração. Para Chuang (2001), a escolha da localização de uma instalação deve considerar objetivos quantitativos (econômicos) como custo do terreno, proximidade com fornecedores e varejistas, 
disponibilidade de serviços públicos, assim como objetivos qualitativos como políticas do governo, fatores ambientais e qualidade de vida.

Os critérios para localização de instalações são utilizados em métodos e modelos que auxiliam o tomador de decisão a escolher o melhor local para sua unidade produtiva ou de serviço. Dentre os métodos para localização de instalação temos o método do centro de gravidade que baseia-se no princípio de que todos os locais candidatos têm um valor resultante da soma de todos os custos incluídos (Silva, 2004), métodos heurísticos que podem não encontrar a solução ótima, porém aproximam-se da realidade (Carvalho, 1979; Ballou, 2001), os métodos de simulação que tentam reproduzir uma situação real e são mais flexíveis (Ballou, 2001; Mapa, 2007), método de programação linear que visa a maximização ou minimização de uma função objetivo considerando as restrições (Heiderich, 2011; Carvalho, 1979) e os métodos multicritérios de tomada de decisão que são utilizados em casos em que existem critérios tangíveis e intangíveis ao mesmo tempo (Ross \& Soland, 1980; Jannuzzi et al., 2009; Saaty, 1991; Mousavi et al., 2013).

Além dos métodos, existem modelos matemáticos que são utilizados com frequência para localização de facilidades e podem ser utilizados para localização de instalações únicas ou múltiplas (Aikens, 1985; Lopes \& Caixeta, 2000; Bowersox \& Closs, 2001), os modelos dinâmicos que lidam com problemas difíceis de serem resolvidos devido à incerteza (Mapa, 2007; Rocha, 2008), modelos estáticos-determinísticos como o modelo das medianas e da cobertura de conjuntos (Rocha, 2008), modelos estocásticos que tratam as incertezas, como tempo de viagem, custo de construção, quantidade de locais (Mapa, 2007; Rocha, 2008) e os modelos de localização contínuo e em redes, sendo viável a localização em todo o plano no primeiro caso e as distâncias são computadas como caminhos mais curtos, no segundo (Klose \& Drexl, 2005; Rosário et al., 2002).

\subsection{Métodos multicritérios de tomada de decisão}

A complexidade verificada nas últimas décadas decorrente do aumento do número de informações e da necessidade de utilizá-las no processo decisório fez com que surgissem novos métodos para localização de instalações na tentativa de alcançar maior assertividade nas tomadas de decisão.

Neste sentido, métodos multicritérios de tomada de decisão surgiram como métodos de apoio que são vistos como ferramentas matemáticas, eficazes para resolução de problemas em que existem critérios conflitantes (Brans \& Mareschal, 2005).
Tais métodos fornecem ao usuário uma classificação e ranqueamento dos locais candidatos (Saaty, 1991; Saaty \& Vargas, 2012).

Para Vincke (1992), a vantagem da utilização de métodos multicritérios ocorre pelo fato de que não há, em geral, decisões que sejam simultaneamente ótimas sob todos os pontos de análise, fazendo com que ocorra desta forma, a seleção da melhor opção possível.

A diferença entre os métodos multicritérios de tomada de decisão e outros métodos se dá pelo fato de considerarem diversos aspectos e avaliarem as ações por meio de um conjunto de critérios, derivando de cada conjunto uma função matemática que serve para medir o desempenho de cada ação (Ensslin, 2001).

Na Figura 1, visualiza-se a montagem de um sistema decisório para os métodos multicritério de tomada de decisão.

Conforme visualiza-se na Figura 1, a construção esquemática para a resolução de um problema multicritério de tomada de decisão inicia-se com a definição do problema, a identificação das restrições, os critérios e, por fim, as alternativas a serem avaliadas e selecionadas pelo tomador de decisão. Isto ocorre por meio do cruzamento dos critérios com as alternativas e dos critérios com o objetivo final.

Para a resolução de problemas que abrangem múltiplos critérios, existem diversos métodos tais como $A H P$, PROMETHEE, ELECTRE (Rodrigues et al., 2001; Vilas Boas, 2006), MAC, TOPSIS, TODIM (Rodrigues et al., 2001).

Métodos multicritérios para tomada de decisão podem ser utilizados para diferentes escolhas como para a seleção de uma modalidade de transporte (Saaty, 1991); para operações estratégicas de mercado, processo e design de produto, planejamento e programação de recursos e gerenciamento da cadeia de suprimentos (Subramanian \& Ramanathan, 2012); para a seleção de qual produto agrícola plantar (Silva et al., 2006); para a seleção de fornecedores (Tramarico et al. 2012; Deng et al. 2014); para a decisão entre a terceirização ou internalização de atividades (Reis et al., 2013); e até mesmo para a escolha da escola em que seu filho pode estudar (Saaty, 1991).

Dentro da gama de possibilidades existentes para a utilização de métodos multicritérios de tomada de decisão surge a utilização para a localização de instalações devido a sua flexibilidade para a tomada de decisão, podendo o problema ser definido com intensa participação das pessoas responsáveis pela execução (Gomes, 2009). Particularmente, torna-se interessante para o setor público, no qual seus gestores têm que tomar decisões para a sociedade como um todo, sem a priorização de um determinado grupo, abrindo a possibilidade da decisão ser mais participativa, contemplando diferentes interesses. 


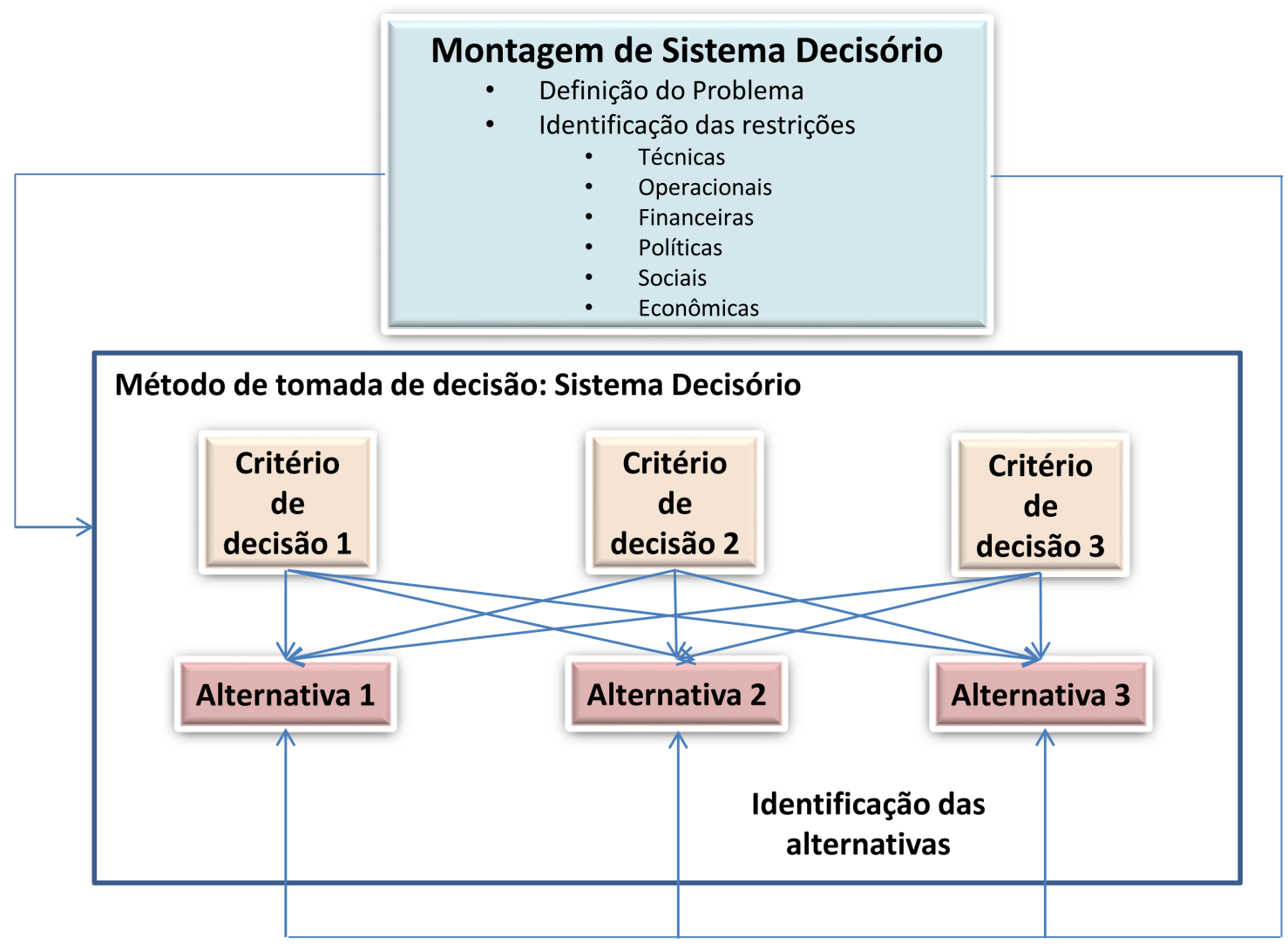

Figura 1. Montagem do sistema decisório nos métodos de tomada de decisão. Fonte: Adaptado pelos autores de Rodrigues et al. (2001).

\subsection{Método multicritério Analytic Hierarchy Process - AHP}

O método multicritério Analytic Hierarchy Process - AHP surgiu no final da década de 60 do século XX e foi desenvolvido pelo matemático Thomas L. Saaty, quando trabalhava para a Agência de Controle de Armas e Desarmamento do Departamento de Estado Americano (Forman \& Selly, 2002). Segundo os autores, foi devido à observação de Saaty sobre a dificuldade de comunicação entre os membros do governo americano que surgiu a motivação para desenvolver um método de apoio à tomada de decisão.

$\mathrm{O}$ método $A H P$ foi desenvolvido para modelar problemas desestruturados do cotidiano das pessoas, por elas tomarem decisões sem necessariamente ter a noção exata da importância dos parâmetros utilizados (Saaty, 1980; Saaty 1991).

No método $A H P$, ocorre a elucidação das preferências dos tomadores de decisão por meio dos julgamentos subjetivos dos participantes, fazendo com que quantifiquem numericamente seus julgamentos, levando em consideração a importância relativa dos fatores que estão sob análise (Yang \& Lee, 1997; Vargas, 1990).

A utilização do método $A H P$ é bem aceita pelos usuários devido ao fato de que, muitas vezes, os critérios que estão em análise pelos usuários do método são conflitantes (Hartman \& Goltz, 2002), sendo o método próprio para estas situações.

Além de o método AHP permitir a resolução de problemas com critérios conflitantes, uma das vantagens apontadas por Gomes (2009) se deve ao fato de o método permitir a participação de diversas pessoas, como é o caso da gestão pública, em que decisões envolvem diversos atores, diversos critérios e múltiplas alternativas e consequências.

Por fim, a utilização do método $A H P$ é também indicada pelo fato de mensurar critérios tangíveis com intangíveis, por meio de uma escala de razão, podendo o problema ser divido em diversas partes, relacionando-as e conectando os juízos de comparação com o objetivo final da aplicação (Vargas, 1990).

\subsection{Método $A H P$ para localização de instalação}

Segundo Randhawa \& West (1995), para a localização de instalações, o método $A H P$ abrange quatro etapas: identificar um conjunto de critérios para avaliar locais candidatos; desenvolver pesos para os critérios que reflitam a importância relativa de cada um deles no ambiente de decisão; avaliar 
cada local com respeito a cada critério; e agregar os pesos de cada critério em uma classificação geral.

No Quadro 1, observa-se uma síntese de estudos com a utilização do método $A H P$ para localização de instalações. Os estudos estão apresentados em ordem do mais recente para o mais antigo.

Conforme visualiza-se no Quadro 1, a aplicação do método $A H P$ no auxílio à tomada de decisão em localização de instalações tem sido utilizado em diferentes países e com diferentes objetivos, desde localização de instalações industriais, até mesmo na localização de uma usina termoelétrica. Além da variedade, destaca-se a possibilidade de se mesclar a utilização do método $A H P$ com outros métodos como: a lógica fuzzy (Wang et al., 2014; Nazari et al., 2012; Ozdagoglu, 2012); o método Delphi (Wu et al., 2007); o método Quality Function Deployment - QFD; e com uma variação do próprio $A H P$ que é o Analytic Network Process - ANP.

\section{Unidade de Pronto Atendimento - UPA $24 \mathrm{~h}$}

Com a instituição da Política Nacional de Atenção às Urgências, criada pela Portaria $\mathrm{n}^{\circ} 1.863$, de 29 de setembro de 2003, surgem medidas por parte do Governo Federal da expansão da rede de atenção à saúde. Dentro deste contexto, o Governo cria as

Quadro 1. Síntese de estudos relacionados com a utilização do método $A H P$ para localização de instalações.

\begin{tabular}{|c|c|c|c|c|c|}
\hline $\mathbf{N}^{\mathbf{0}}$ & Título & Ano & Autor(es) & Objetivo & Observações \\
\hline 1 & $\begin{array}{l}\text { Definição de } \\
\text { localidade } \\
\text { para instalação } \\
\text { industrial com } \\
\text { apoio do método } \\
\text { de análise } \\
\text { hierárquica } \\
\text { (AHP) }\end{array}$ & 2014 & $\begin{array}{l}\text { José Roberto } \\
\text { Xavier Alves; } \\
\text { João Murta } \\
\text { Alves (Alves \& } \\
\text { Alves, 2014) }\end{array}$ & $\begin{array}{l}\text { Auxiliar } \\
\text { na tomada } \\
\text { de decisão } \\
\text { locacional de } \\
\text { uma unidade } \\
\text { fabril do ramo } \\
\text { automotivo }\end{array}$ & $\begin{array}{l}\text { Os autores fazem a análise dos fatores que } \\
\text { devem ser considerados para a localização de } \\
\text { uma unidade fabril, aplicando o método AHP } \\
\text { em um estudo de caso na indústria automotiva. } \\
\text { Os critérios utilizados foram os custos } \\
\text { logísticos, custo com mão de obra, maturidade } \\
\text { da localização (desenvolvimento regional), } \\
\text { índice de força de trabalho e incentivos fiscais. }\end{array}$ \\
\hline 2 & $\begin{array}{l}\text { Potential } \\
\text { Hospital } \\
\text { Location } \\
\text { Selection Using } \\
\text { Fuzzy-AHP: Na } \\
\text { Empirical Study } \\
\text { in a Rural India }\end{array}$ & 2013 & $\begin{array}{l}\text { Debmallya } \\
\text { Chatterje; Bani } \\
\text { Mukherjee } \\
\text { (Chatterjee \& } \\
\text { Mukherjee, } \\
\text { 2013) }\end{array}$ & $\begin{array}{l}\text { Localizar um } \\
\text { hospital na zona } \\
\text { rural da Índia }\end{array}$ & $\begin{array}{l}\text { Os autores mesclaram o método da lógica } \\
\text { fuzzy com o método de análise hierárquica } \\
\text { desenvolvendo para isto } 3 \text { critérios e } \\
11 \text { subcritérios considerados relevantes } \\
\text { locorregionalmente. Os subcritérios custo da } \\
\text { terra, densidade populacional e proximidade } \\
\text { com transportes públicos foram os mais } \\
\text { relevantes para a localização de uma unidade } \\
\text { hospitalar. }\end{array}$ \\
\hline 3 & $\begin{array}{l}\text { The Aplication } \\
\text { of AHP } \\
\text { Approach for } \\
\text { Evaluating } \\
\text { Location } \\
\text { Selection } \\
\text { Elements of } \\
\text { Retail Store: A } \\
\text { Case of Clothing } \\
\text { Store }\end{array}$ & 2013 & $\begin{array}{l}\text { Mehmet Akalin; } \\
\text { Gulden Turhan; } \\
\text { Azize Sahin } \\
\text { (Akalin et al., } \\
\text { 2013) }\end{array}$ & $\begin{array}{l}\text { Determinar a } \\
\text { importância } \\
\text { relativa de } \\
\text { critérios de } \\
\text { localização } \\
\text { assim como } \\
\text { localizar uma } \\
\text { loja de roupas }\end{array}$ & $\begin{array}{l}\text { Os autores abordam a importância da } \\
\text { localização assertiva acerca de lojas de varejo } \\
\text { que podem determinar o sucesso ou o fracasso } \\
\text { nos negócios. Os principais critérios utilizados } \\
\text { pelos autores foram: população, o varejo, os } \\
\text { custos e a competitividade. Esses } 4 \text { critérios } \\
\text { são derivados de outros } 13 \text { subcritérios. }\end{array}$ \\
\hline 4 & $\begin{array}{l}\text { Locating Urban } \\
\text { Transit Hubs: } \\
\text { Multicriteria } \\
\text { Model and Case } \\
\text { Study in China }\end{array}$ & 2011 & $\begin{array}{l}\text { Jie Yu; Yue } \\
\text { Liu; Gang-Len } \\
\text { Chang; Wanjing } \\
\text { Ma; Xiaoguang } \\
\text { Yang (Yu et al., } \\
\text { 2011) }\end{array}$ & $\begin{array}{l}\text { Localização de } \\
\text { Terminais de } \\
\text { Transporte }\end{array}$ & $\begin{array}{l}\text { Os autores fizeram a aplicação do método } \\
A H P \text { em conjunto com a lógica fuzzy, para o } \\
\text { ranqueamento e seleção da localização ideal } \\
\text { de um centro de transporte público (ponto de } \\
\text { coleta e transferência de passageiros). }\end{array}$ \\
\hline 5 & $\begin{array}{l}\text { Location of } \\
\text { cargo terminals } \\
\text { in metropolitan } \\
\text { areas of } \\
\text { developing } \\
\text { countries: the } \\
\text { Brazilian case }\end{array}$ & 2011 & $\begin{array}{l}\text { Licinio da Silva } \\
\text { Portugal; Andréa } \\
\text { Vaz Morgado; } \\
\text { Orlando } \\
\text { Lima Júnior } \\
\text { (Portugal, et al. } \\
\text { 2011) }\end{array}$ & $\begin{array}{l}\text { Localização de } \\
\text { Terminais de } \\
\text { Carga em área } \\
\text { urbana na região } \\
\text { metropolitana do } \\
\text { Rio de Janeiro. }\end{array}$ & $\begin{array}{l}\text { Os autores destacam a possibilidade de } \\
\text { utilização do método } A H P \text { para o processo } \\
\text { de tomada de decisão, contribuindo com os } \\
\text { formuladores de políticas de desenvolvimento, } \\
\text { tirando desta forma a parcialidade da decisão. }\end{array}$ \\
\hline
\end{tabular}


Quadro 1. Continuação...

\begin{tabular}{|c|c|c|c|c|c|}
\hline $\mathrm{N}^{\mathbf{0}}$ & Título & Ano & Autor(es) & Objetivo & Observações \\
\hline 6 & $\begin{array}{l}\text { A Decision } \\
\text { Framework } \\
\text { for Location } \\
\text { Selection in } \\
\text { Global Supply } \\
\text { Chains }\end{array}$ & 2007 & $\begin{array}{l}\text { N. } \\
\text { Viswanadham; } \\
\text { S. Kameshwaran } \\
\text { (Viswanadham } \\
\& \\
\text { Kameshwaran, } \\
\text { 2007) }\end{array}$ & $\begin{array}{l}\text { Seleção de } \\
\text { um local para } \\
\text { investimento }\end{array}$ & $\begin{array}{l}\text { Os autores destacaram a possibilidade da } \\
\text { utilização do método } A H P \text { como ferramenta } \\
\text { para medir a atratividade de mercado, como } \\
\text { suporte para agências de desenvolvimento } \\
\text { na avaliação locacional. Outro destaque } \\
\text { que fazem é a utilização da análise de } \\
\text { sensibilidade, que pode ajudar a identificar } \\
\text { qual o nível de melhoria necessária que cada } \\
\text { critério deve ter para atender às demandas dos } \\
\text { interessados. }\end{array}$ \\
\hline 7 & $\begin{array}{l}\text { Optimal } \\
\text { selection of } \\
\text { location for } \\
\text { Taiwanese } \\
\text { hospitals } \\
\text { to ensure a } \\
\text { competitive } \\
\text { advantage } \\
\text { by using } \\
\text { the analytic } \\
\text { hierarchy } \\
\text { process and } \\
\text { sensitivity } \\
\text { analysis }\end{array}$ & 2007 & $\begin{array}{l}\text { Cheng-Ru Wu; } \\
\text { Chin-Tsai Lin; } \\
\text { Huang-Chu } \\
\text { Chen (Wu et al., } \\
\text { 2007) }\end{array}$ & $\begin{array}{l}\text { Seleção da } \\
\text { localização ideal } \\
\text { de hospitais em } \\
\text { Taiwan }\end{array}$ & $\begin{array}{l}\text { Houve aplicação do método } A H P \text { em conjunto } \\
\text { com o método Delphi (que considera que a } \\
\text { utilização de especialistas é mais precisa do } \\
\text { que estimativas de um grupo informal. Tal } \\
\text { método se baseia na experiência de vários } \\
\text { especialistas). A contribuição que os autores } \\
\text { trouxeram foi a construção de uma referência } \\
\text { para administradores hospitalares para o } \\
\text { estabelecimento de um meio padronizado } \\
\text { para escolha dos locais de novas unidades } \\
\text { hospitalares. }\end{array}$ \\
\hline 8 & $\begin{array}{l}\text { An analytic } \\
\text { model for } \\
\text { locating facilities } \\
\text { strategically }\end{array}$ & 2006 & $\begin{array}{l}\text { Fariborz Y. } \\
\text { Partovi (Partovi, } \\
\text { 2006) }\end{array}$ & $\begin{array}{l}\text { Localização de } \\
\text { Instalações }\end{array}$ & $\begin{array}{l}\text { Houve utilização do método AHP em conjunto } \\
\text { com outros } 2 \text { métodos ( } Q F D \text { - Quality } \\
\text { Function Deployment e método ANP - } \\
\text { Analytic Network Process). A utilização de } \\
\text { métodos multicritérios é destacada pelo autor } \\
\text { pelo fato de adicionarem precisão quantitativa } \\
\text { para o processo decisório. Uma contribuição } \\
\text { do artigo foi a consideração, no modelo de } \\
\text { localização, tanto dos critérios internos quanto } \\
\text { externos à empresa. }\end{array}$ \\
\hline 9 & $\begin{array}{l}\text { Análise de } \\
\text { Decisão } \\
\text { Multicritério } \\
\text { na Localização } \\
\text { de Usinas } \\
\text { Termoelétricas } \\
\text { Utilizando SIG }\end{array}$ & 2005 & $\begin{array}{l}\text { Kátia Lívia } \\
\text { Zambon; } \\
\text { Adriano Alber } \\
\text { de França } \\
\text { M. Carneiro; } \\
\text { Antônio Nélson } \\
\text { Rodrigues da } \\
\text { Silva; Jean } \\
\text { Cesari Negri } \\
\text { (Zambon et al., } \\
\text { 2005) }\end{array}$ & $\begin{array}{l}\text { Localização } \\
\text { de Usinas } \\
\text { Termoelétricas } \\
\text { (UTEs) }\end{array}$ & $\begin{array}{l}\text { O método } A H P \text { foi utilizado em conjunto } \\
\text { com Sistema de Informação Geográfica (SIG) } \\
\text { para a localização das UTEs. Os autores } \\
\text { identificaram que, apesar de o método } A H P \text { e } \\
\text { do SIG serem duas áreas distintas, pode haver } \\
\text { benefícios na utilização combinada deles. }\end{array}$ \\
\hline 10 & $\begin{array}{l}\text { An AHP } \\
\text { decision model } \\
\text { for facility } \\
\text { location } \\
\text { selection }\end{array}$ & 1997 & $\begin{array}{l}\text { Jiaqin Yang; } \\
\text { Huei Lee (Yang } \\
\text { \& Lee, 1997) }\end{array}$ & $\begin{array}{l}\text { Localização } \\
\text { de instalações } \\
\text { - Exemplo } \\
\text { do artigo: } \\
\text { Localização de } \\
\text { Arena de Hóquei } \\
\text { na Finlândia }\end{array}$ & $\begin{array}{l}\text { No artigo os autores mencionam que, } \\
\text { no estudo de caso, a primeira opção de } \\
\text { localização (definida simplesmente por } \\
\text { critérios políticos) acabou ficando com a } 3^{\text {a }} \\
\text { opção quando utilizado o método } A H P \text {, mesmo } \\
\text { sendo eles envolvidos (políticos), na utilização } \\
\text { do método. Isto reforça a eficácia do método, } \\
\text { tirando a parcialidade das decisões e sua } \\
\text { contribuição na sua tomada. }\end{array}$ \\
\hline
\end{tabular}

Fonte: Elaborado pelos autores. 
Unidades de Pronto Atendimento - UPA 24 h que têm a função de garantir atendimento médico adequado para as urgências de baixa e média complexidade e reduzir a superlotação das emergências nos hospitais (Relatório do Programa de Aceleração do Crescimento - PAC 2).

Segundo a Portaria 2.648 de 7 de novembro de 2011, a UPA 24 h é uma unidade de atendimento intermediária, que deve fornecer retaguarda às urgências da Rede de Atenção Básica à Saúde e, em caso de necessidade, realizar a transferência dos pacientes para serviços hospitalares de média e alta complexidade.

Por meio da Portaria $n^{\circ} 1.020$ de 13 de maio de 2009, estabeleceram-se as diretrizes para as UPA $24 \mathrm{~h}$, com destaque para as seguintes competências/responsabilidades: funcionamento $24 \mathrm{~h}$ por dia, todos os dias da semana; acolhimento dos pacientes e familiares sempre que buscarem atendimento na UPA $24 \mathrm{~h}$; estabelecimento de protocolos de atendimento clínico, de triagem e de procedimentos administrativos; possuir equipe interdisciplinar compatível com seu porte; fornecer retaguarda às urgências atendidas pela Atenção Básica; e prestar apoio diagnóstico (realização de raios $X$, exames laboratoriais, eletrocardiograma) e terapêutico nas 24 horas do dia.

A abrangência de atendimento das UPA $24 \mathrm{~h}$ envolve casos como: febre alta, fraturas, cortes, infarto e derrame (Brasil, 2013).

Em relação ao porte, existem três portes de UPA $24 \mathrm{~h}$ que são: Porte I para municípios com população entre 50 mil e 100 mil habitantes; Porte II para municípios com porte entre 100 mil e 200 mil habitantes; e Porte III para municípios com população entre 200 mil e 300 mil habitantes.

Na Tabela 1, apresenta-se a classificação das UPA $24 \mathrm{~h}$ por porte, a população, área física, $\mathrm{n}^{\mathrm{o}} \mathrm{de}$ atendimentos previstos, $\mathrm{n}^{\circ}$ de médicos por plantão e, por último, $\mathrm{n}^{\mathrm{o}}$ mínimo de leitos para atendimento.

\section{Forma de aplicação do método AHP}

$\mathrm{O}$ resultado obtido pela aplicação do método AHP acontece por meio da comparação paritária dos critérios, subcritérios e alternativas, quantificando-os (Saaty, 1991).
Para a construção do método, existe a necessidade de seguir três passos para se chegar ao resultado final que são: decomposição do problema em critérios, sendo que os critérios serão decompostos em subcritérios até o menor nível da hierarquia; análise comparativa paritária entre os critérios por meio de uma escala numérica; e síntese das prioridades por meio do cálculo de autovetores ou análise do mínimo quadrado, sendo o processo repetido para cada nível da hierarquia até a decisão final.

A utilização de uma hierarquia é a busca da resolução do problema por meio das interações entre os diversos níveis hierárquicos, não somente entre os elementos do mesmo nível (Saaty, 1991; Ke et al., 2012).

Na Figura 2, visualiza-se a representação gráfica de uma hierarquia.

Na Figura 2, visualiza-se uma representação da estruturação de uma hierarquia para a resolução de um problema por meio do método $A H P$ : tem-se no Nível 1 o "Objetivo Final”; no Nível 2, apresentam-se os "Critérios"; no Nível 3, os "Subcritérios"; e, por fim, no Nível 4, as alternativas.

Segundo Vargas (1990), os pesos finais ou globais são obtidos por adição de todas as contribuições dos critérios de uma mesma hierarquia, no que diz respeito a todos os critérios no nível acima, o que é conhecido como o princípio da composição da hierarquia. Isto acontece por meio da comparação paritária, entre os critérios, subcritérios e alternativas (Saaty, 1991).

Na Tabela 2, visualiza-se a escala desenvolvida pelo criador do método para que os julgamentos dos critérios, subcritérios e alternativas sejam realizados.

Para a aplicação do método, matrizes são preenchidas com base na escala fundamental visualizada na Tabela 2 . Das matrizes são calculados os autovetores máximos e os autovalores máximos (ou "lâmbida" $\lambda_{\max }$ ), conforme visualiza-se na Figura 3.

Visualiza-se na Figura 3 o cálculo do autovetor máximo, que ocorre primeiramente pelo cálculo dos somatórios dos pesos da avaliação. Na sequência, calcula-se a matriz de comparação par a par normalizada, dividindo cada elemento da matriz original pelo somatório dos pesos da avaliação (Figura 4).

Por fim, para calcular o autovetor máximo, divide-se o somatório das linhas da nova matriz normalizada

Tabela 1. Classificação das UPA 24 h pelo porte, população, área física, $\mathrm{n}^{\circ}$ de estabelecimentos, médicos e leitos.

\begin{tabular}{cccccc}
\hline $\begin{array}{l}\text { UPA } \\
\text { 24h }\end{array}$ & $\begin{array}{c}\text { População da Área de } \\
\text { Abrangência da UPA 24 h } \\
\text { (em mil hab.) }\end{array}$ & $\begin{array}{c}\text { Área Física } \\
\text { Mínima }\end{array}$ & $\begin{array}{c}\mathbf{N}^{\mathbf{o}} \text { de atendimentos } \\
\text { médicos em 24 h }\end{array}$ & $\begin{array}{c}\mathbf{N}^{\mathbf{0}} \text { mínimo de } \\
\text { médicos por } \\
\text { plantão }\end{array}$ & $\begin{array}{c}\mathbf{N}^{\mathbf{0}} \text { mínimo } \\
\text { de leitos de } \\
\text { observação }\end{array}$ \\
\hline Porte I & 50 a 100 & $700 \mathrm{~m}^{2}$ & até 150 pacientes & 2 médicos & 7 leitos \\
Porte II & 100.001 a 150 & $1.000 \mathrm{~m}^{2}$ & até 300 pacientes & 4 médicos & 11 leitos \\
Porte III & 200.001 a 300 & $1.300 \mathrm{~m}^{2}$ & até 450 pacientes & 6 médicos & 15 leitos \\
\hline
\end{tabular}

Fonte: Elaborado pelos autores através da Portaria $N^{\circ} 1601$, de 7 de julho de 2011 (Brasil, 2011). 


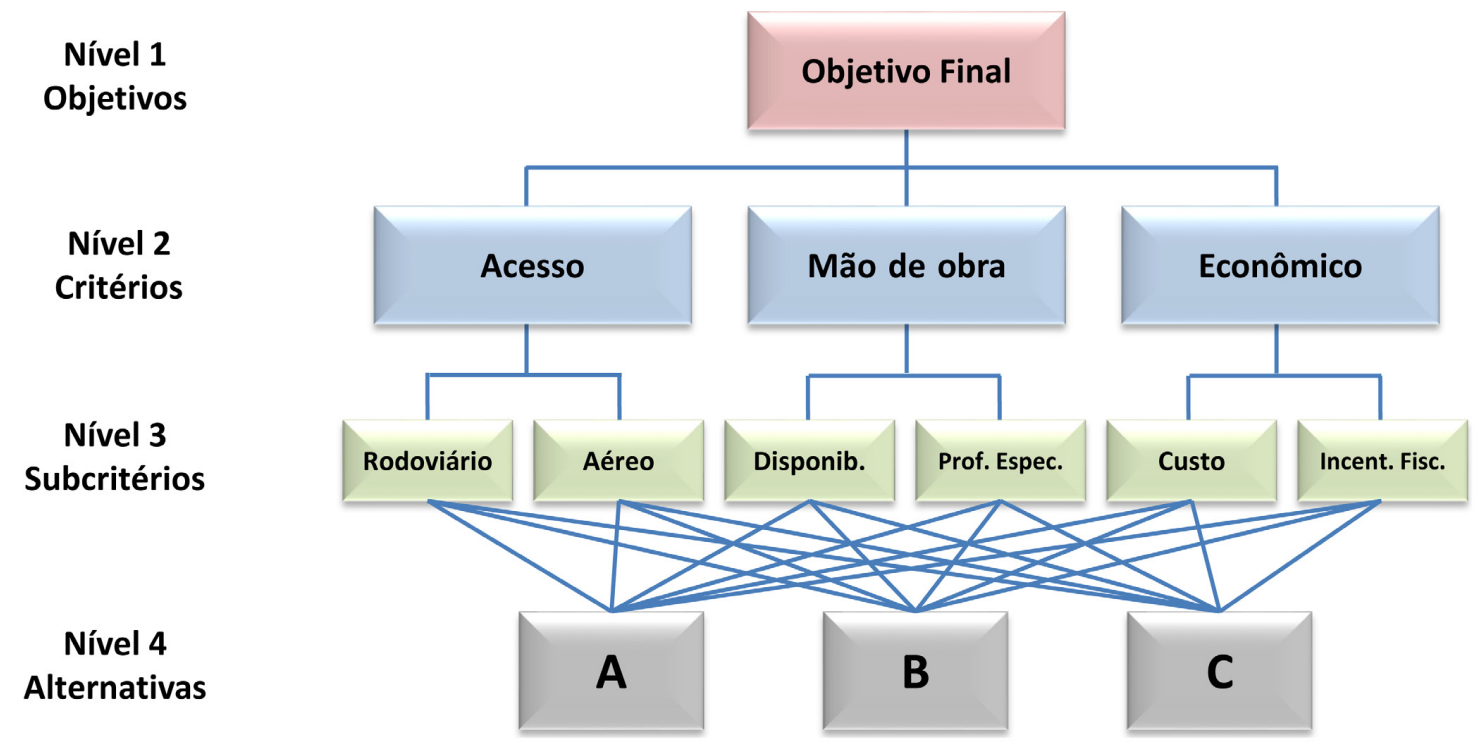

Figura 2. Representação Gráfica de uma hierarquia. Fonte: Elaborado pelos autores.

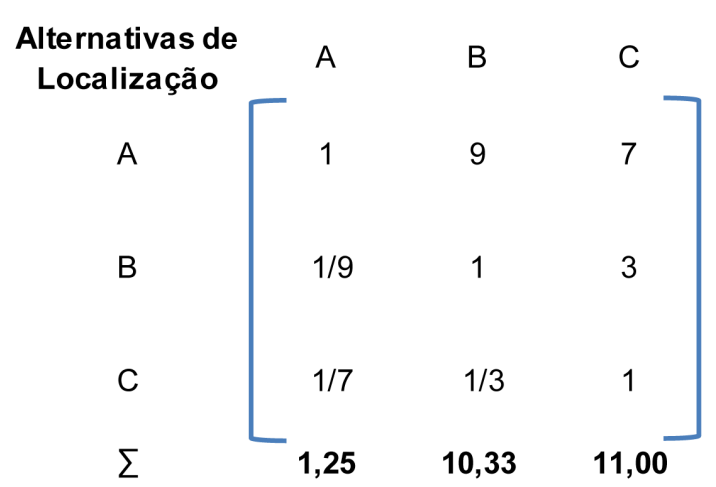

Figura 3. Cálculo dos somatórios dos pesos da avaliação.

\begin{tabular}{|c|c|c|c|c|}
\hline $\begin{array}{l}\text { Alternativas de } \\
\text { Localização }\end{array}$ & A & B & C & $\Sigma$ \\
\hline A & 0,797 & 0,871 & 0,636 & 2,305 \\
\hline B & 0,089 & 0,097 & 0,273 & 0,458 \\
\hline C & 0,114 & 0,032 & 0,091 & 0,237 \\
\hline
\end{tabular}

Figura 4. Matriz de comparação par a par normalizada.

pelo somatório dos somatórios. Assim, obtêm-se o autovetor máximo. Tal cálculo visualiza-se na Tabela 3 .

O próximo passo é calcular o autovalor máximo, por meio da multiplicação da matriz original (Figura 3) pelo autovetor máximo (Tabela 3). Na Figura 5 visualiza-se o cálculo.

Depois do cálculo do autovalor, verifica-se o Índice de Consistência (Consistency Index), que mede a consistência das comparações. Aconselha-se que este índice fique abaixo de 0,20 . O cálculo é realizado pela Equação 1:

$$
C I=\frac{\lambda \max -n}{(n-1)}
$$

Por meio da Equação 1, para o exemplo, o CI é igual a 0,20 .

Por fim, calcula-se a Razão de Consistência $-C R$, do julgamento do avaliador. O cálculo da Razão de Consistência ( $C R$ - Consistency Ratio) também considera um erro aleatório, que está relacionado com a ordem da matriz, dado pelo Índice de Consistência Aleatória (RI - Random Consistency Index) (Saaty, 1991). A Tabela 4 apresenta o cálculo dos Índices de Consistência Aleatória para matrizes de ordem 1 a 10.

Para se calcular o $C R$, utiliza-se a Equação 2:

$$
C R=\frac{C I}{R I}
$$

Para o exemplo, o $C R$ é igual a $0,20 / 0,58$ (0,58 extraído da Tabela 4), encontrando uma Razão de Consistência de 0,34. Recomenda-se que, caso a Razão de Consistência seja maior do que 0,20 , o julgamento do avaliador seja revisto.

\section{Aplicação do método $A H P$ para a localização de uma UPA $24 \mathrm{~h}$}

Problemas complexos, como o de localização de unidades de saúde, requerem a aplicação de métodos que permitam avaliar os benefícios que a assertividade na localização possa trazer para a sociedade. Neste sentido, o método AHP permite avaliar o problema de localização da UPA $24 \mathrm{~h}$ com condições de trazer 
Tabela 2. Escala fundamental de números absolutos.

\begin{tabular}{cll}
\hline $\begin{array}{c}\text { Intensidade de } \\
\text { Importância }\end{array}$ & \multicolumn{1}{c}{ Definição } & \multicolumn{1}{c}{ Explicação } \\
\hline 1 & Mesma Importância & $\begin{array}{l}\text { As duas atividades contribuem igualmente para } \\
\text { o objetivo. }\end{array}$ \\
\hline 3 & Importância pequena de uma sobre a outra & $\begin{array}{l}\text { A experiência e o julgamento favorecem } \\
\text { levemente uma atividade em relação a outra. }\end{array}$ \\
\hline 5 & Importância grande ou essencial & $\begin{array}{l}\text { A experiência e o julgamento favorecem } \\
\text { fortemente uma atividade em relação a outra. }\end{array}$ \\
\hline 7 & Importância muito grande ou demonstrada & $\begin{array}{l}\text { Uma atividade é muito fortemente favorecida } \\
\text { em relação a outra; sua dominação de } \\
\text { importância é demonstrada na prática. }\end{array}$ \\
\hline $2,4,6,8$ & Importância absoluta & $\begin{array}{l}\text { A evidência favorece uma atividade em relação } \\
\text { a outra com o mais alto grau de certeza. }\end{array}$ \\
\hline Valores intermediários entre os valores & $\begin{array}{l}\text { Quando se procura uma condição de } \\
\text { compromisso entre duas definições. }\end{array}$ \\
\hline
\end{tabular}

Fonte: Elaborado pelos autores a partir de Saaty (1991).

Tabela 3. Cálculo do Autovetor Máximo.

\begin{tabular}{cc}
\hline & Autovetor \\
\hline $2,305 / 3,000$ & 0,768 \\
$0,458 / 3,000$ & 0,153 \\
$0,237 / 3,000$ & 0,079 \\
\hline
\end{tabular}

Fonte: elaborado pelo autor.

\begin{tabular}{|c|c|c|c|c|c|c|}
\hline 1 & 9 & 7 & & 0,768 & & 2,70 \\
\hline $1 / 9$ & 1 & 3 & $\mathbf{x}$ & 0,153 & $=$ & 0,48 \\
\hline $1 / 7$ & $1 / 3$ & 1 & & 0,079 & & 0,24 \\
\hline & & & & & $\Sigma$ & $\begin{array}{c}3,41 \\
\text { autovalor } \\
\text { máx ou } \lambda_{\text {má }}\end{array}$ \\
\hline
\end{tabular}

Figura 5. Cálculo do Autovalor.

resultados satisfatórios para a sociedade. Para a aplicação do método $A H P$, selecionou-se um município do interior do Estado de São Paulo a partir da análise de publicações do Governo Federal no Diário Oficial da União no qual observou-se o referido município como beneficiário em receber a UPA $24 \mathrm{~h}$.

$\mathrm{O}$ município selecionado tem uma população de aproximadamente 70 mil habitantes, dista 120 quilômetros da capital do estado e possui 57 estabelecimentos de saúde sendo 23 públicos municipais.

A partir da seleção do município objeto de análise, estabeleceu-se uma cooperação com a gestão municipal, para que o estudo pudesse ser realizado, e foram convidas cinco profissionais das secretarias de saúde e desenvolvimento urbano a participarem da pesquisa. Na primeira etapa, construiu-se uma lista de critérios e subcritérios para localização da unidade de saúde. Em seguida, a prefeitura municipal apresentou uma lista com seis terrenos públicos possíveis de receber a UPA $24 \mathrm{~h}$, sendo estes locais as alternativas de localização utilizadas no estudo.

Na Figura 6, observa-se a montagem da hierarquia gerada a partir da lista de critérios, subcritérios e alternativas definidas com os membros participantes do estudo:

A partir da estruturação da hierarquia que se visualiza na Figura 6, foram aplicados questionários para os cinco membros da gestão municipal. O exemplo de preenchimento visualiza-se na Figura 7.

No exemplo da Figura 7, o respondente indica que o "Local 1" possui uma importância pequena sobre o "Local 2", conforme a escala fundamental apresentada na Tabela 2.

Desta forma, todos os locais foram comparados em relação a cada subcritério, cada subcritério foi comparado em relação a cada critério, e cada critério foi comparado em relação ao objetivo final, que é o de selecionar o melhor local de instalação de uma UPA $24 \mathrm{~h}$.

Na Figura 8, apresenta-se um exemplo da comparação das alternativas de localização em relação ao subcritério "Condição Socioeconômica Local" (que envolve tanto a condição de locomoção quanto à condição econômica da população de ter um serviço de atendimento médico privado, por exemplo).

Foram aplicadas 10 matrizes idênticas à Figura 8, depois foram aplicadas mais 3 matrizes de comparação de cada subcritério em relação ao seu critério e mais 1 matriz de comparação de cada critério em relação ao objetivo final.

\section{Resultados da aplicação}

A partir da consolidação dos dados dos questionários conforme Figura 8, que foram elaborados a partir da estrutura hierárquica apresentada na Figura 6 , as matrizes de comparação paritária foram inseridas no software Expert Choice 11, na versão estudantil. Existe uma limitação na versão estudantil do software no que diz respeito ao número de níveis hierárquicos. Porém, para este estudo, não houve este problema pelo fato 
Tabela 4. Índice de Consistência Aleatória.

\begin{tabular}{ccccccccccc}
\hline Ordem da matriz & $\mathbf{1}$ & $\mathbf{2}$ & $\mathbf{3}$ & $\mathbf{4}$ & $\mathbf{5}$ & $\mathbf{6}$ & $\mathbf{7}$ & $\mathbf{8}$ & $\mathbf{9}$ & $\mathbf{1 0}$ \\
\hline RI & 0.00 & 0.00 & 0.58 & 0.90 & 1.12 & 1.24 & 1.32 & 1.41 & 1.45 & 1.49 \\
\hline
\end{tabular}

Fonte: Adaptado de Saaty (1991).

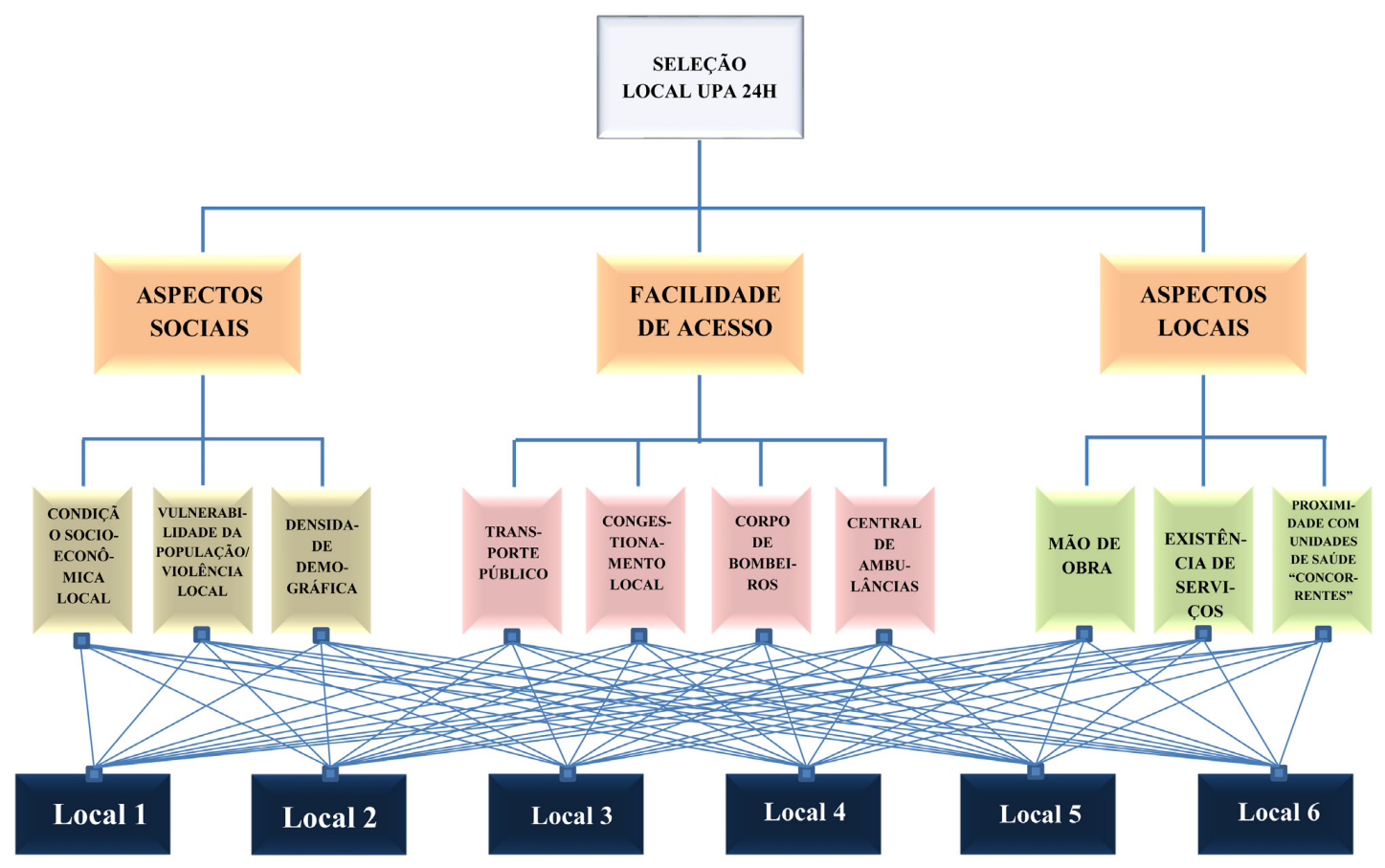

Figura 6. Representação da hierarquia do problema de localização da UPA 24 h. Fonte: Elaborado pelos autores.

\begin{tabular}{l|l|l|l|l|l|l|l|l|l|l|l|l|l|l|l|l|l|l|} 
Local 1 & 9 & 8 & 7 & 6 & 5 & 4 & $\bigcirc$ & 2 & 1 & 2 & 3 & 4 & 5 & 6 & 7 & 8 & 9 & Local 2 \\
\hline
\end{tabular}

Figura 7. Exemplo de preenchimento do questionário. Fonte: Elaborado pelos autores.

\begin{tabular}{|c|c|c|c|c|c|c|c|c|c|c|c|c|c|c|c|c|c|c|}
\hline Local 1 & 9 & 8 & 7 & 6 & 5 & 4 & 3 & 2 & 1 & 2 & 3 & 4 & 5 & 6 & 7 & 8 & 9 & Local 2 \\
\hline Local 1 & 9 & 8 & 7 & 6 & 5 & 4 & 3 & 2 & 1 & 2 & 3 & 4 & 5 & 6 & 7 & 8 & 9 & Local 3 \\
\hline Local 1 & 9 & 8 & 7 & 6 & 5 & 4 & 3 & 2 & 1 & 2 & 3 & 4 & 5 & 6 & 7 & 8 & 9 & Local 4 \\
\hline Local 1 & 9 & 8 & 7 & 6 & 5 & 4 & 3 & 2 & 1 & 2 & 3 & 4 & 5 & 6 & 7 & 8 & 9 & Local 5 \\
\hline Local 1 & 9 & 8 & 7 & 6 & 5 & 4 & 3 & 2 & 1 & 2 & 3 & 4 & 5 & 6 & 7 & 8 & 9 & Local 6 \\
\hline Local 2 & 9 & 8 & 7 & 6 & 5 & 4 & 3 & 2 & 1 & 2 & 3 & 4 & 5 & 6 & 7 & 8 & 9 & Local 3 \\
\hline Local 2 & 9 & 8 & 7 & 6 & 5 & 4 & 3 & 2 & 1 & 2 & 3 & 4 & 5 & 6 & 7 & 8 & 9 & Local 4 \\
\hline Local 2 & 9 & 8 & 7 & 6 & 5 & 4 & 3 & 2 & 1 & 2 & 3 & 4 & 5 & 6 & 7 & 8 & 9 & Local 5 \\
\hline Local 2 & 9 & 8 & 7 & 6 & 5 & 4 & 3 & 2 & 1 & 2 & 3 & 4 & 5 & 6 & 7 & 8 & 9 & Local 6 \\
\hline Local 3 & 9 & 8 & 7 & 6 & 5 & 4 & 3 & 2 & 1 & 2 & 3 & 4 & 5 & 6 & 7 & 8 & 9 & Local 4 \\
\hline Local 3 & 9 & 8 & 7 & 6 & 5 & 4 & 3 & 2 & 1 & 2 & 3 & 4 & 5 & 6 & 7 & 8 & 9 & Local 5 \\
\hline Local 3 & 9 & 8 & 7 & 6 & 5 & 4 & 3 & 2 & 1 & 2 & 3 & 4 & 5 & 6 & 7 & 8 & 9 & Local 6 \\
\hline Local 4 & 9 & 8 & 7 & 6 & 5 & 4 & 3 & 2 & 1 & 2 & 3 & 4 & 5 & 6 & 7 & 8 & 9 & Local 5 \\
\hline Local 4 & 9 & 8 & 7 & 6 & 5 & 4 & 3 & 2 & 1 & 2 & 3 & 4 & 5 & 6 & 7 & 8 & 9 & Local 6 \\
\hline Local 5 & 9 & 8 & 7 & 6 & 5 & 4 & 3 & 2 & 1 & 2 & 3 & 4 & 5 & 6 & 7 & 8 & 9 & Local 6 \\
\hline
\end{tabular}

Figura 8. Comparações paritárias para o caso da localização da UPA 24 h. Fonte: Elaborado pelos autores. 
Quadro 2. Resultado das comparações paritárias.

\begin{tabular}{|c|c|c|c|c|c|c|c|}
\hline \multicolumn{7}{|c|}{ Localizar a UPA 24h } \\
\hline Respondente & Local 1 & Local 2 & Local 3 & Local 4 & Local 5 & Local 6 & Inconsistência \\
\hline 1 & 0,138 & 0,133 & 0,122 & 0,091 & 0,154 & 0,362 & 0,14 \\
\hline 2 & 0,181 & 0,159 & 0,141 & 0,178 & 0,168 & 0,173 & 0,16 \\
\hline 3 & 0,312 & 0,167 & 0,125 & 0,137 & 0,135 & 0,124 & 0,10 \\
\hline 4 & 0,430 & 0,172 & 0,115 & 0,069 & 0,112 & 0,102 & 0,17 \\
\hline 5 & 0,248 & 0,085 & 0,150 & 0,132 & 0,169 & 0,217 & 0,04 \\
\hline Média & 0,262 & 0,143 & 0,131 & 0,121 & 0,148 & 0,196 & 0,122 \\
\hline
\end{tabular}

Fonte: Elaborado pelos autores.

Quadro 3. Classificação dos locais candidatos com sua pontuação.

\begin{tabular}{|c|c|c|}
\hline Classificação & Local & Pontuação \\
\hline $1^{\text {o }}$ & Local 1 & 0,262 \\
\hline $2^{\text {o }}$ & Local 6 & 0,196 \\
\hline $3^{\circ}$ & Local 5 & 0,148 \\
\hline $4^{\text {o }}$ & Local 2 & 0,143 \\
\hline $5^{\circ}$ & Local 3 & 0,131 \\
\hline $6^{\circ}$ & Local 4 & 0,121 \\
\hline
\end{tabular}

Fonte: Elaborado pelos autores.

de existir o número máximo de níveis hierárquicos possíveis para a versão estudantil.

O software realiza as operações matemáticas apresentadas na seção 4 .

Depois da inserção dos dados no software, apresenta-se no Quadro 2 a consolidação em relação ao objetivo final.

Conforme visualiza-se no Quadro 2, verifica-se que a "inconsistência" ficou dentro do limite aceito pelo método, conforme a Equação 1 e Equação 2, que é abaixo de 0,20. O mesmo vale para a inconsistência "global" (última linha da tabela).

Visualiza-se ainda em destaque no Quadro 2 o local candidato que teve melhor desempenho nas comparações paritárias realizadas por cada respondente. No Quadro 3, visualiza-se o ranqueamento dos locais candidatos, com sua classificação e pontuação.

Conforme visualiza-se no Quadro 3, o objetivo da construção do método foi atendido, conseguindo-se ranquear e identificar aquele local que, na visão dos participantes da pesquisa, foi o local que atendeu em maior intensidade às suas análises.

Além da análise do objetivo final com a aplicação do método $A H P$, pôde-se também realizar outras duas observações, que foram:

1) Dentre os critérios selecionados pelos participantes do estudo, qual foi o mais importante; e

2) Dentre os subcritérios derivados de cada critério, aquele que foi o mais importante.

No Quadro 4, visualiza-se a importância de cada critério, por cada um dos respondentes.
Pode-se visualizar no Quadro 4, que o critério "Aspectos Sociais" foi aquele que recebeu, na média, a maior pontuação, quando comparado com o objetivo final de localizar a UPA $24 \mathrm{~h}$. Observa-se que, para o respondente 2, o critério "Aspectos Sociais" teve a mesma importância do que o critério "Facilidade de Acesso".

Nos três quadros seguintes, apresenta-se dentro de cada critério, quais subcritérios foram os mais bem avaliados pelos respondentes.

No Quadro 5, visualiza-se dentro do critério "Aspectos Sociais" o subcritério que teve, na opinião dos respondentes, a maior importância sobre os demais.

Visualiza-se, no Quadro 5, que o subcritério "Vulnerabilidade da População/Violência Local" foi o que obteve, na média, a melhor pontuação pelos respondentes. Ressalta-se que este subcritério foi unânime entre os respondentes, demonstrando a importância que este subcritério tem sobre os demais.

No Quadro 6, visualiza-se dentro do critério "Facilidade de Acesso" o subcritério que teve, na opinião dos respondentes, a maior importância sobre os demais.

Observa-se no Quadro 6 que o subcritério “Transporte Público" foi o mais bem avaliado pelos respondentes. Apesar de termos hoje grandes congestionamentos nas cidades brasileiras, o subcritério "Congestionamento Local" não foi o principal considerado para a localização de uma UPA $24 \mathrm{~h}$. Isso demonstra que o foco no transporte coletivo de qualidade deve ser buscado pelos governantes em detrimento da priorização do transporte utilitário.

Por fim, apresenta-se no Quadro 7 o subcritério que foi melhor pontuado, em comparação com o critério "Aspectos Locais".

Visualiza-se no Quadro 7 que o subcritério "Mão de Obra" foi o melhor classificado pelos respondentes em relação ao critério "Aspectos Locais”. Observa-se ainda no Quadro 7 que as comparações realizadas destes subcritérios foram as que mais tiveram divergência entre os respondentes, visto que os três subcritérios foram melhor avaliados por ao menos um respondente, diferentemente do que ocorreu com os outros subcritérios e critérios apresentados nos Quadros 5 e 6. 
Quadro 4. Pontuação dos critérios por cada respondente.

\begin{tabular}{|c|c|c|c|}
\hline \multirow{2}{*}{ Respondente } & \multicolumn{3}{|c|}{ Critérios } \\
\cline { 2 - 4 } & Aspectos Sociais & Facilidade de Acesso & Aspectos Locais \\
\hline 1 & 0,271 & 0,644 & 0,085 \\
\hline 2 & 0,467 & 0,467 & 0,067 \\
\hline 3 & 0,584 & 0,135 & 0,281 \\
\hline 4 & 0,770 & 0,063 & 0,167 \\
\hline 5 & 0,600 & 0,200 & 0,200 \\
\hline Média & 0,538 & 0,302 & 0,160 \\
\hline
\end{tabular}

Fonte: Elaborado pelos autores.

Quadro 5. Subcritérios mais pontuados dentro do critério "Aspectos Sociais".

\begin{tabular}{|c|c|c|c|}
\hline \multirow{2}{*}{ Respondente } & \multicolumn{2}{|c|}{ Aspectos Sociais } \\
\cline { 2 - 4 } & $\begin{array}{c}\text { Condição Socioeconômica } \\
\text { Local }\end{array}$ & $\begin{array}{c}\text { Vulnerabilidade da } \\
\text { População/Violência Local }\end{array}$ & Densidade Demográfica \\
\hline 1 & 0,258 & 0,637 & 0,105 \\
\hline 2 & 0,191 & 0,761 & 0,048 \\
\hline 3 & 0,251 & 0,673 & 0,075 \\
\hline 4 & 0,170 & 0,780 & 0,050 \\
\hline 5 & 0,429 & 0,429 & 0,143 \\
\hline Média & 0,260 & 0,656 & 0,084 \\
\hline
\end{tabular}

Fonte: Elaborado pelos autores.

Quadro 6. Subcritérios mais pontuados dentro do critério "Facilidade de Acesso".

\begin{tabular}{|c|c|c|c|c|}
\hline \multirow{2}{*}{ Respondente } & \multicolumn{4}{|c|}{ Facilidade de Acesso } \\
\cline { 2 - 5 } & Transporte Público & $\begin{array}{c}\text { Congestionamento } \\
\text { Local }\end{array}$ & Corpo de Bombeiros & $\begin{array}{c}\text { Central de } \\
\text { Ambulâncias }\end{array}$ \\
\hline 1 & 0,579 & 0,220 & 0,092 & 0,11 \\
\hline 2 & 0,130 & 0,502 & 0,228 & 0,14 \\
\hline 3 & 0,159 & 0,161 & 0,234 & 0,445 \\
\hline 4 & 0,572 & 0,052 & 0,101 & 0,275 \\
\hline 5 & 0,506 & 0,292 & 0,169 & 0,032 \\
\hline Média & 0,389 & 0,245 & 0,165 & 0,200 \\
\hline
\end{tabular}

Fonte: Elaborado pelos autores.

Quadro 7. Subcritérios mais pontuados dentro do critério "Aspectos Locais".

\begin{tabular}{|c|c|c|c|}
\hline \multirow{2}{*}{ Respondente } & Mão de obra & Existência de Serviços & $\begin{array}{c}\text { Proximidade com Unidades } \\
\text { de Saúde }\end{array}$ \\
\cline { 2 - 4 } & 0,175 & 0,281 & 0,544 \\
\hline 1 & 0,747 & 0,193 & 0,06 \\
\hline 2 & 0,304 & 0,575 & 0,121 \\
\hline 3 & 0,796 & 0,079 & 0,125 \\
\hline 5 & 0,474 & 0,474 & 0,053 \\
\hline Média & 0,499 & 0,320 & 0,181 \\
\hline
\end{tabular}

Fonte: Elaborado pelos autores.

\section{Considerações finais}

Resgatando o objetivo do presente trabalho, destaca-se que a principal contribuição que este trabalho pretende trazer consiste na apresentação de um método multicritério para tomada de decisão utilizado para localização de instalações, com foco na localização de um equipamento de saúde, ou seja, uma unidade de saúde voltada para a prestação de serviços à sociedade.

O trabalho buscou apresentar a construção do método $A H P$, suas operações matemáticas, a forma de construir os critérios, subcritérios e alternativas para a aplicação do método, construindo também os 
questionários que podem ser utilizados para facilitar a avaliação paritária que os participantes devem realizar para se atingir o objetivo final.

Pôde-se observar que o método conseguiu atingir o objetivo final de ranquear e classificar os locais candidatos, dando embasamento para que o gestor local consiga tomar sua decisão. É importante ressaltar que o método $A H P$ pode ser mais uma ferramenta em que os gestores públicos podem lançar mão para tomar uma decisão isonômica, alheia a interesses particulares, minimizando o risco de tendenciosidade no processo decisório, conseguindo desta forma maximizar o bem-estar da sociedade em detrimento do individual.

O modelo desenvolvido neste trabalho pode servir como modelo para outras aplicações voltadas para a localização de unidades de saúde, pois deixa como contribuição os critérios e subcritérios construídos e possíveis de serem utilizados como referência para outros estudos.

Como sugestões para trabalhos futuros, fica a possibilidade de se mesclar o método $A H P$ com outros métodos de tomada de decisão, com outras técnicas para localização de instalações, visando aprimorar o resultado e atingir maior assertividade no resultado final, trazendo desta forma resultados cada vez melhores para a sociedade.

\section{Referências}

Aikens, C. H. (1985). Facility location models for distribution planning. European Journal of Operational Research, 22(3), 263-279. http://dx.doi.org/10.1016/03772217(85)90246-2.

Akalin, M., Turhan, G., \& Sahin, A. (2013). The AppLICATION OfAHP approach for evaluating location selection elements for retail store: a case of clothing store. International Journal of Research in Business and Social Science, 2(4).

Alves, J. R. X., \& Alves, J. M. (2014). Definição de localidade para instalação industrial com o apoio do método de análise hierárquica (AHP). Production Journal, 25(1), 13-26.

Ballou, R. H. (2001). Gerenciamento da cadeia de suprimentos: planejamento, organização e logística empresarial (4 ed.). Porto Alegre: The Bookman. 532 p.

Ballou, R. H. (2006).Gerenciamento da cadeia de suprimentos: logística empresarial. Porto Alegre: Bookman. 616 p.

Bowersox, D. J., \& Closs, D. J. (2001). Logística empresarial: o processo de integração da cadeia de suprimento. São Paulo: Editora Atlas.

Brans, J. P., \& Mareschal, B. (2005). Multiple criteria decision analysis - state of the art. Dordrecht: Kluwer Academic Publishers.
Brasil. Ministério da Saúde. (2011, 7 de julho). Portaria $N^{o}$ 1.601, de 7 de julho de 2011.Estabelece diretrizes para a implantação do componente Unidades de Pronto Atendimento (UPA 24h) e o conjunto de serviços de urgência 24 horas da Rede de Atenção às Urgências, em conformidade com a Politica Nacional de Atenção às Urgências ( seção 1, pp. 70-72). Brasília, DF: Diário Oficial da União.

Brasil. Ministério da Saúde. (2013). Portal da saúde. Unidades de Pronto Atendimento UPA 24h. Recuperado em 28 de agosto de 2013, de http://portalsaude.saude. gov.br/index.php/o-ministerio/principal/secretarias/ sas/upa-24horas.

Carvalho, L. D. R. (1979). Uma contribuição ao estudo da localização de instalações intermediárias em redes de transporte (Dissertação de mestrado). Instituto Militar de Engenharia, Rio de Janeiro.

Chatterjee, D.; Mukherjee, B. (2013). Potential hospital location selection using fuzzy-AHP: an empirical study in Rural India. International Journal of Innovative Technology and Research, 1(4), 304-314.

Chuang, P. T. (2001). Combining the analytic hierarchy process and quality function deployment for a location decision from a requirement perspective. International Journal of Advanced Manufacturing Technology, 18(11), 842-849. http://dx.doi.org/10.1007/s001700170010.

Closs; D. J.; Thompson, C. K. (1992). Logistics physical resource management. Journal of Business Logistics, 13(2), 269-283.

Covas, M. T., Silva, C. A., \& Dias, L. C. (2013). On locating sustainable data centers in Portugal: problem structuring and GIS-based analysis. Sustainable Computing: Informatics and Systems, 3, 27-35.

Daskin, M. S. (1995). Network and discrete locationmodels, algorithms and aplications. New York: John Wiley \& Sons.

Deng, X., Hu, Y., Deng, Y., \& Mahadevan, S. (2014). Supplier selection using AHP methodology extended by D numbers. Expert Systems with Applications, 41(1), 156-167. http://dx.doi.org/10.1016/j.eswa.2013.07.018.

Ensslin, L. (2001). Apoio à decisão: Metodologia para a estruturação de problemas e avaliação multicritério de alternativas. Florianópolis: Insular.

Fernandes, A. S. A. (2007). Políticas públicas: definição, evolução e o caso brasileiro. In H. DANTAS, \& J. P. Martins Jr. (Eds.), Introdução à política brasileira, São Paulo: Paulus.

Forman, E. H., \& Selly, M. A. (2002). Decision by objectives: How to convince others that you are right. Singapore: World Scientific. 402 p. Recuperado em 25 de outubro de 2012, de http://professorforman.com/ DecisionByObjectives/Chapter1.PDF.

Gomes, K. G. A. (2009). Um método multicritério para localização de unidades de celulares de intendência da FAB (Dissertação de mestrado). Departamento 
de Engenharia de Produção, Pontifícia Universidade Católica do Rio de Janeiro, Rio de Janeiro.

Hartman, D. H., \& Goltz, M. N. (2002). Application of the analytic hierarchy process to select characterization and risk-based decision-making and management methods for hazardous waste sites. Environmental Engineering and Policy, 3(1), 1-7. http://dx.doi.org/10.1007/ s100220100035.

Heiderich, N. N. L. (2011). Modelagem matemática para localização ótima de usinas de incineração com recuperação energética de resíduos sólidos domiciliares: uma aplicação para Região Metropolitana da Baixada Santista e Litoral Norte (Dissertação de mestrado). Escola Superior de Agricultura Luiz de Queiroz, Universidade de São Paulo, Piracicaba.

Jannuzzi, P. M., Miranda, W. L., \& Silva, D. S. G. (2009). Análise multicritério e tomada de decisão em políticas públicas: aspectos metodológicos, aplicativo operacional e aplicações. Informática Pública, 11(1), 69-87.

Ke, G. Y., Li, K., \& HIPEL, K. W. (2012). An integrated multiple criteria preference ranking approach to the Canadian west coast port congestion conflict. Expert Systems with Applications, 39(10), 9181-9190. http:// dx.doi.org/10.1016/j.eswa.2012.02.086.

Klose, A., \& Drexl, A. (2005). Facility location models for distribution system design. European Journal of Operational Research, 162(1), 4-29.

Lopes, R. L., \& Caixeta, J. V., Fo. (2000). Suinocultura no Estado de Goiás: aplicação de um modelo de localização. Pesquisa Operacional, 20(2), 213-232. http://dx.doi. org/10.1590/S0101-74382000000200006.

Lorena, L. A. N., Senne, E. L. F., Paiva, J. A. C., \& Pereira, M. A. (2001). Integração de Modelos de Localização a Sistemas de Informações Geográficas. Gestão \& Produção, 8(2), 180-195. http://dx.doi.org/10.1590/ S0104-530X2001000200006.

Mapa, S. M. S. (2007). Localização-Alocação de instalações com sistema de informações geográficas e modelagem matemática (Dissertação de mestrado). Universidade Federal de Itajubá, Itajubá.

Moreira, D. A. (1996). Administração da produção e operações (2 ed.). São Paulo: Pioneira.

Mousavi, S. M., Tavakkoli-Moghaddam, R., Heydar, M., \& Ebrahimnejad, S. (2013). Multi-criteria decision making for plant location selection: an integrated delphiAHP-PROMETHEE methodology. Arabian Journal for Science and Engineering, 38(5), 1255-1268. http:// dx.doi.org/10.1007/s13369-012-0361-8.

Nazari, A., Salarirad, M. M., \& Bazzazi, A. A. (2012). Landfill site selection by decision-making tools based on fuzzy multi-attribute decision making method. Environ Earth Sci, 65(6), 1631-1642. http://dx.doi.org/10.1007/ s12665-011-1137-2.

Ozdagoglu, A. (2012). A multi-criteria decision-making methodology on the selection of facility location: fuzzy
ANP. International Journal of Advanced Manufacturing Technology, 59(5-8), 787-803. http://dx.doi.org/10.1007/ s00170-011-3505-1.

Partovi, F. Y. (2006). An analytic model for location facilities strategically. Omega - The International Journal of Management Science, 34(1), 41-55.

Portugal, L. S., Morgado, A. V., \& Lima, O., Jr. (2011). Location of cargo terminals in metropolitan areas of developing countries: the Brazilian case. Journal of Transport Geography, 19(4), 900-910. http://dx.doi. org/10.1016/j.jtrangeo.2010.11.005.

Randhawa, S. U., \& West, T. M. (1995). An integrated approach to facility location problems. Computers \& Industrial Engineering, 29(1-4), 261-265. http://dx.doi. org/10.1016/0360-8352(95)00082-C.

Reis, L. P., Ladeira, M. B., \& Fernandes, J. M. (2013). Contribuição do método Analytic Hierarchy Process (AHP) para auxílio ao processo decisório de terceirizar ou internalizar atividades no contexto de uma empresa de base tecnológica. Revista Produção Online, 13(4), 1325. http://dx.doi.org/10.14488/1676-1901.v13i4.1326.

Ribeiro, A., \& Antunes, A. P. (2002). A GIS-based decisionsupport tool for public facility planning. Environment and Planning. B, Planning \& Design, 29(4), 553-569. http://dx.doi.org/10.1068/b1281.

Rocha, B. O. (2008). Utilização de modelos de localização para dinamização do fluxo reverso de pneus inservíveis (Dissertação de mestrado). Universidade Federal do Ceará, Fortaleza.

Rodrigues, F. H., Martins, W. C., \& Monteiro, A. B. F. C. (2001). O Processo de Decisão Baseado em um Método de Análise Hierárquica na Tomada de Decisão Sobre Investimentos. In J. V. Caixeta Fo. \& R. S. Martins (Eds.), Gestão logística do transporte de cargas. São Paulo: Atlas.

Romero, B. C. (2006). Análise da localização de plataformas logísticas: uma aplicação ao caso da ETSP - Entreposto Terminal São Paulo - da CEAGESP (Dissertação de mestrado). Escola Politécnica, Universidade de São Paulo. São Paulo.

Rosário, R. R. L., Carnieri, C., \& Steiner, M. T. A. (2002). Proposta de solução para o problema das p-medianas na localização de unidades de saúde 24 horas. In Anais do XXII Encontro Nacional de Engenharia de Produção. Curitiba: ABEPRO.

Ross, G. T., \& Soland, R. M. (1980). A multicriteria approach to the location of public facilities. European Journal of Operational Research, 4(5), 307-321. http://dx.doi. org/10.1016/0377-2217(80)90142-3.

Saaty, T. L. (1980). The analytic hierarchy process. New York: McGraw-Hill.

Saaty, T. L. (1991). Método de análise hierárquica. São Paulo: Makron Books. 
Saaty, T. L., \& Vargas, L. G. (2012). Models, methods, concepts \& applications of the analytic hirarchy process (2 ed., International Series in Operations Research \& Management Science, 175). New York: Springer. 345 p.

Silva, J. T. M., Cabrera, P. A. L., \& Teixeira, L. A. A. (2006). Aplicação de um método de análise hierárquica no processo de tomada de decisão: um estudo com empreendedor agrícola da região de Divino/MG. Revista Gestão e Planejamento, 7(14), 19-30.

Silva, M. R. (2004). Uma contribuição ao problema de localização de Terminais de Consolidação no transporte de carga parcelada (Dissertação de mestrado). Escola Politécnica, Universidade de São Paulo, São Paulo.

Stock, R. (1983). Distance and the utilization of health facilities in rural Nigeria. Social Science \& Medicine (1982), 17(9), 563-570. http://dx.doi.org/10.1016/02779536(83)90298-8. PMid:6879255.

Subramanian, N., \& Ramanathan, R. (2012). A review of applications of Analytic Hierarchy Process in operations management. International Journal of Production Economics, 138(2), 215-241. http://dx.doi.org/10.1016/j. ijpe.2012.03.036.

Tramarico, C. L., Salomon, V. A. P., Marins, F. A. S, \& Muniz, J., Jr. (2012). Modelagem com AHP e BOCR para seleção de prestadores de serviços logísticos. Revista Eletrônica Pesquisa Operacional para o Desenvolvimento, 4(2), 139-159.

Vargas, L. G. (1990). An overview of the Analytic Hierarchy Process and its applications. European Journal of Operational Research, 48(1), 2-8. http:// dx.doi.org/10.1016/0377-2217(90)90056-H.

Vilas Boas, C. L. (2006). Modelo multicritérios de apoio à decisão aplicada ao uso múltiplo de reservatórios: estudo da barragem do ribeirão João Leite (Dissertação de mestrado). Departamento de Economia, Universidade de Brasília, Brasília.

Vincke, P. (1992). Multicriteria decision-aid. Chichester: John Wiley \& Sons.

Viswanadham, N., \& Kameshwaran, S. A. (2007). A decision Framework for Location Selection in Global Supply Chains. In IEEE Conference on Automation Science and Engineering (pp. 704-709). Scottsdale: IEEE.

Wang, Y., Jung, K.-A., Yeo, G.-T., \& Chou, C.-C. (2014). Selecting a cruise port of location using the fuzzy-ahp method: a case study in East Asia. Tourism Management, 42, 262-270. http://dx.doi.org/10.1016/j. tourman.2013.11.005.

Wu, C. R., Lin, C. T., \& Chen, H. C. (2007). Optimal selection of location for Taiwanese hospitals to ensure a competitive advantage by using the analytic hierarchy process and sensitivity analysis. Building and Environment, 42(3), 1431-1444. http://dx.doi. org/10.1016/j.buildenv.2005.12.016.

Yang, J., \& Lee, H. (1997). An AHP decision model for facility location selection. Facilities, 15(Iss: 9), 241254. http://dx.doi.org/10.1108/02632779710178785.

Yu, J., Liu, Y., Chang, G.-L., Ma, W., \& Yang, X. (2011). Locating urban transit hubs: multicriteria model and case study in China. Journal of Transportation Engineering, 137(12), 944-952. http://dx.doi.org/10.1061/(ASCE) TE.1943-5436.0000275.

Zambon, K. L., Carneiro, A. A. F. M., Silva, A. N. R., \& Negri, J. C. (2005). Análise de decisão multicritério na localização de usinas termoelétricas utilizando SIG. Pesquisa Operacional, 25(2), 183-199. http://dx.doi. org/10.1590/S0101-74382005000200002. 